\title{
Resistência Quantitativa à Ferrugem da Folha em Genótipos de Aveia Branca: III - Correlação de Componentes de Resistência entre si e com a Intensidade de Doença no Campo*
}

\author{
Márcia S. Chaves ${ }^{1}$, José A. Martinelli² \& Luiz C. Federizzi ${ }^{3}$ \\ ${ }^{1}$ Embrapa Trigo, Cx. Postal 451, CEP 99001-970, Passo Fundo, RS, e-mail: mchaves@ cnpt.embrapa.br; ${ }^{2}$ Departamento de \\ Fitossanidade, ${ }^{3}$ Departamento de Plantas de Lavoura, Faculdade de Agronomia, Universidade Federal do Rio Grande \\ do Sul, Cx. Postal 776, CEP 91540-000, Porto Alegre, RS
}

(Aceito para publicação em 09/04/2003)

Autor para correspondência: Márcia Soares Chaves

CHAVES, M.S. , MARTINELLI, J.A. \& FEDERIZZI, L.C. Resistência quantitativa à ferrugem da folha em genótipos de aveia branca: III Correlação de componentes de resistência entre si e com a intensidade de doença no campo. Fitopatologia Brasileira 29:197-200. 2004.

\section{RESUMO}

A seleção de genótipos com resistência quantitativa à ferrugem da folha da aveia (Avena sativa), baseada nos componentes que a condicionam, necessita do conhecimento da associação destes componentes entre si e deles com a quantidade de doença no campo, representada pela área abaixo da curva de progresso da doença (AACPD). Este trabalho objetivou determinar estas correlações, a partir de resultados de ensaios realizados previamente, em que 31 genótipos de aveia branca tiveram sua reação à ferrugem determinada no campo e seus componentes de resistência quantificados. As correlações encontradas foram geralmente baixas, tanto dos componentes entre si, como deles com a intensidade da doença no campo. As correlações mais altas, e consistentes entre os anos, com a AACPD foram da eficiência de infecção em plântulas, do período de latência e do comprimento de pústulas em plantas adultas. Estes dados sugerem que os componentes citados podem ter uma influência um pouco maior que os demais sobre a expressão da resistência parcial a campo. Entretanto, a baixa correlação entre os componentes medidos, indica que a seleção de genótipos, nesta interação patógeno-hospedeiro, não deve ser realizada com base em apenas um componente de resistência. Os resultados sugerem que a expressão da resistência parcial à ferrugem da folha da aveia não é condicionada apenas por um componente de resistência, mas sim pelo efeito conjunto de todos eles. Além disto, é possível que mecanismos diferenciados estejam atuando em cada genótipo, de forma que os componentes de resistência mais importantes para um não sejam os mesmos para outro.

Palavras-chave adicionais: Puccinia coronata f. sp. avenae, Avena sativa, seleção fenotípica, AACPD, período de latência, eficiência de infecção, tamanho de pústula, esporulação.

\section{ABSTRACT}

Quantitative resistance to crown rust in white oat genotypes: III - Correlation of its resistance components with each other and with the amount of disease in the field

Selection of genotypes for quantitative resistance to oat crown rust, based on its components, needs the knowledge of the association of these components with each other and with the amount of disease in the field, represented by AUDPC. This work aimed to determine these correlations, based on results of previous trials, in which the reaction of 31 white oat genotypes was tested and the resistance components were quantified. Correlations were usually low for the resistance components with each other and for these components with the amount of disease in the field. Higher correlations, consistent among years, with AUDPC were infection frequency in

A resistência quantitativa é um tipo de resistência incompleta, que proporciona uma baixa taxa de desenvolvimento da moléstia no campo (Parlevliet, 1979; 1985), a qual resulta da combinação de componentes de resistência como baixa frequiência de infecção, período latente longo, pústulas pequenas, baixa produção de esporos por pústula e período

*Parte da tese de doutorado do primeiro autor. Universidade Federal do Rio Grande do Sul (2001).

${ }^{2,3}$ Bolsista de produtividade do $\mathrm{CNPq}$ seedlings and latent period and pustule size in adult plants. All other possible correlations were very low. These data suggest that the resistance components mentioned can influence the expression of quantitative resistance in the field in a somewhat important manner. Nevertheless, the low correlation of resistance components with each other indicates that genotype selection, in this host-pathogen interaction, must not be based on a single resistance component assessment. The correlation analysis suggests that the expression of quantitative resistance to oat crown rust is not conditioned by a single resistance component but by the group effect of all of them. In addition, it is possible that different mechanisms are involved for each genotype, in such a way that the more important resistance component in one genotype may not be the same for another.

infeccioso curto (Ohm \& Shaner, 1976; Sztejmberg \& Whal, 1976; Parlevliet, 1979; Whal et al, 1980).

A avaliação deste tipo de resistência deve ser realizada no campo, e pode ser feita através da quantificação da proporção do tecido do hospedeiro afetado várias vezes durante o desenvolvimento da epidemia. Esta forma de avaliação possibilita o cálculo da área abaixo da curva de progresso da doença (AACPD) (Parlevliet, 1988), considerada como um bom indicador da resistência quantitativa (Parlevliet, 
1985; 1988). No caso das ferrugens dos cereais, a importância dos componentes de resistência para a redução da moléstia no campo, e conseqüentemente da AACPD, pode variar, dependendo patossistema. Para a ferrugem da folha do trigo (Triticum aestivum L.) e da cevada (Hordeum vulgare L.), por exemplo, o período de latência é o componente mais importante, já para a ferrugem amarela do trigo, a freqüência de infecção e a produção de esporos parecem ser os componentes mais importantes (Parlevliet, 1988).

Assim, pode-se pensar em selecionar genótipos através da mensuração de um único componente de resistência, se este apresentar alta relação de associação com a AACPD. De fato, este procedimento pode ser de grande utilidade para agilizar a seleção em programas de melhoramento. No entanto, a seleção baseada em apenas um componente só será tão eficiente quanto a seleção realizada no campo, se houver também alta correlação entre os componentes de resistência (Parlevliet, 1988).

A ocorrência de resistência quantitativa à ferrugem da folha causada por Puccinia coronataf. sp. avenae Fraser $\&$ Led em aveia (Avena sativa L.), expressa em diferentes níveis, foi verificada em condições de campo em genótipos de aveia branca desenvolvidos no sul do Brasil e adaptados a este ambiente (Chaves, 2003a). Os genótipos com os melhores níveis de resistência quantitativa, apresentaram a melhor combinação de componentes de resistência favoráveis, não parecendo haver um componente responsável isoladamente pela expressão da característica a campo (Chaves, 2003b).

Os objetivos deste trabalho foram: 1) estabelecer a correlação entre os componentes de resistência previamente avaliados sob condições controladas e de campo entre si, e deles com a AACPD calculada nos ensaios de campo e; 2) determinar se a seleção de genótipos da aveia com resistência quantitativa à ferrugem da folha pode ser realizada de forma eficiente através de um ou mais destes componentes.

As seguintes correlações foram estabelecidas: a) dos componentes de resistência eficiência de infecção, período de latência, comprimento de pústulas e produção de esporos por pústula de cada genótipo, quantificados por Chaves (2003b) entre si, e b) dos componentes acima citados com a AACPD de cada genótipo avaliado no campo por Chaves (2003a) nos anos de 1998, 1999 e 2000. Foram usadas as médias de tratamento (genótipos) das análises estatísticas para compor os pares de dados, os quais tiveram o grau de associação testados pelo teste t. O programa utilizado foi SANEST - Sistema de Análise Estatística para Microcomputadores (Zonta \& Machado, 1984).

As correlações entre os componentes de resistência foram geralmente baixas. Em plântulas, as correlações mais altas foram entre a eficiência de infecção e o comprimento de pústulas e entre período de latência e comprimento de pústulas, sendo estas associações ambas negativas (Tabela 1). No estádio de planta adulta, o período de latência pode estar associado com o comprimento de pústulas, sendo esta correlação igualmente negativa. As correlações entre as demais variáveis foram mais baixas. A correlação entre o comprimento de pústulas e o número de esporos por pústula em folhas coletadas no campo no ano de 1999 não foi significativa

Os coeficientes de correlação entre os componentes de resistência e as AACPDs em 1998, 1999 e 2000 também foram geralmente baixos (Tabela 2). Dentre os componentes avaliados sob condições controladas, a eficiência de infecção em plântulas, o período de latência e o comprimento de pústulas em plantas adultas foram os que apresentaram as maiores correlações com a intensidade de doença no campo (AACPD). Estas correlações foram todas negativas e apresentaram certa consistência entre os anos. Apesar destes valores ficaram em torno de $50 \%$, se referem a parâmetros quantitativos da resistência e portanto, dentro do esperado para o efeito. As correlações entre os demais componentes medidos em condições controladas com a AACPD foram muito baixas. Os componentes de resistência medidos em folhas provenientes dos ensaios de campo não apresentam qualquer relação de associação com a AACPD . Estes dados sugerem que os componentes citados que apresentaram mais alta associação com a AACPD, podem ter uma influência maior sobre a expressão da resistência quantitativa a campo. Entretanto, a baixa correlação entre os componentes medidos (Tabela 1) indica que a seleção, nesta interação patógenohospedeiro, não deve ser realizada com base em apenas um componente como sugerem Brake \& Irwin (1992) e Thomé et al. (1997), pois segundo Parlevliet (1988), o grau de associação entre os componentes é um importante fator para a seleção de genótipos com resistência parcial, e somente se

TABELA 1 - Correlação entre componentes de resistência, em aveia (Avena sativa) à ferrugem da folha, sob condições controladas (Faculdade de Agronomia/UFRGS) e de campo (EEA/UFRGS, Eldorado do Sul, RS) no período de 1998 a 2000

\begin{tabular}{ll}
\hline \hline Variável $^{1}$ & Coeficiente de correlação(r) \\
\hline Condições controladas & \\
Plântula & $-0,25^{*}$ \\
E. I. x P. L. & $-0,46^{* *}$ \\
E. I. x C. P. & $-0,29 * *$ \\
E. I. x E/P & $-0,43^{*}$ \\
P. L. x C. P. & $-0,04^{*}$ \\
P. L. x E/P & $-0,28^{*}$ \\
C. P. x E/P & \\
Planta adulta & $-0,52^{* *}$ \\
P. L. x C. P. & $-0,18^{*}$ \\
P. L. $x$ E/P & $-0,33^{* *}$ \\
C. P. x E/P & \\
Campo & $-0,39 *$ \\
C. P. $x$ E/P (1998) & $-0,20$ ns \\
C. P. $x$ E/P (1999) &
\end{tabular}


Resistência quantitativa à ferrugem da folha em genótipos de aveia...

TABELA 2 - Correlação entre componentes de resistência, em aveia (Avena sativa) à ferrugem, sob condições controladas (Faculdade de Agronomia/UFRGS) e de campo (EEA/UFRGS, Eldorado do Sul, RS) e a área abaixo da curva de progresso da doença no campo (AACPD) em 1998, 1999 e 2000

\begin{tabular}{|c|c|c|c|}
\hline \multirow{3}{*}{ Variável } & \multicolumn{3}{|c|}{ "Coeficiente de correlação (r) } \\
\hline & \multicolumn{3}{|c|}{ AACPD } \\
\hline & 1998 & 1999 & 2000 \\
\hline \multicolumn{4}{|l|}{ Condições controladas } \\
\hline \multicolumn{4}{|l|}{ Plântula } \\
\hline Eficiência de infecção & $-0,55 * *$ & $-0,30 * *$ & $-0,42 * *$ \\
\hline Período de latência & $-0,19 *$ & $-0,34 * *$ & $-0,46 * *$ \\
\hline Comprimento de Pústulas & $0,35 * *$ & $0,29 * *$ & $0,24 * *$ \\
\hline $\mathrm{N}^{\circ}$ de esporos/pústula & $0,26 * *$ & $0,21 * *$ & $0,18 *$ \\
\hline \multicolumn{4}{|l|}{ Planta Adulta } \\
\hline Período de latência & $-0,56 * *$ & $-0,51 * *$ & $-0,50 * *$ \\
\hline Comprimento de Pústulas & $0,30 * *$ & $0,44 * *$ & $0,57 * *$ \\
\hline $\mathrm{N}^{\circ}$ de esporos/pústula & $0,25 * *$ & $0,16 *$ & $0,23 * *$ \\
\hline \multicolumn{4}{|l|}{ Campo } \\
\hline Comprimento de pústulas & $-0,25 \mathrm{~ns}$ & $-0,0002 \mathrm{~ns}$ & \\
\hline $\mathrm{N}^{\circ}$ de esporos/pústulas & $0,06 \mathrm{~ns}$ & $0,18 \mathrm{~ns}$ & \\
\hline
\end{tabular}

ns: não significativo

* :significativo pelo teste $\mathrm{t}$ a $5 \%$ de probabilidade

**: significativo pelo teste $\mathrm{t}$ a $1 \%$ de probabilidade

este for alto, a seleção baseada em apenas um componente será tão eficiente quanto a seleção a campo. A baixa associação encontrada entre os componentes de resistência citados assemelha-se ao que é relatado para a ferrugem do cravo (Dianthus caryophyllus L.), causada por Uromyces caryophillinus (Schrank) J. Schröt (Lorenzini et al, 1999).

Os dados apresentados sugerem que a expressão da resistência parcial à ferrugem da folha da aveia não é condicionada apenas por um componente de resistência, mas sim pelo efeito conjunto de todos eles; semelhante ao que foi relatado para a ferrugem do feijoeiro (Phaseolus vulgaris L.) (Habtu \& Zadoks, 1995). Isso difere do que tem sido relatado para outras interações, em que o período de latência, o tamanho de lesões, a esporulação, e a eficiência de infecção, além de outros componentes, como proporção de lesões esporulando e densidade de pústulas, isolados ou em conjunto, estão altamente associados à resistência parcial verificada a campo, e indicados para a seleção de genótipos (Ohm \& Shanner, 1976; Neervoort \& Parlevliet, 1978; Parlevliet et al. 1980; Ribeiro Júnior et al. 1993). Além disso, é possível que mecanismos diferenciados estejam atuando em cada genótipo, de forma que os componentes de resistência mais importantes para um genótipo não sejam os mesmos para outro, a exemplo do que é relatado para a antracnose da leguminosa Stylosanthes hamata (L.) Taub., causada por Colletotrichum gloeosporioides (Penz.) Penz. \& Sacc. (Iamsupasit et al., 1993).

Este trabalho contempla apenas alguns aspectos da seleção de genótipos em relação à resistência quantitativa à ferrugem da folha da aveia, através da avaliação de seus componentes. Estudos a respeito da herança destas características e o desenvolvimento de marcadores moleculares associados também são de extrema importância neste contexto e certamente tornarão mais ágil o processo de lançamento de cultivares pelos programas de melhoramento. $\mathrm{O}$ conhecimento da diversidade, complexidade e evolução da população da ferrugem da folha, através do monitoramento contínuo das raças predominantes nas regiões produtoras, também é uma importante prerrogativa para que seja alcançado o êxito esperado com a utilização desta estratégia.

\section{REFERÊNCIAS BIBLIOGRÁFICAS}

BRAKE, V.M. \& IRWIN, J.A.G. Partial resistance of oats to Puccinia coronata f. sp. Avenae. Australian Journal of Agricultural Research 43:1217-1227. 1992.

CHAVES, M.S., MARTINELli, J.A. \& FEDERIZZI, L.C. Resistência quantitativa à ferrugem da folha em genótipos de aveia branca: I - Caracterização da reação em condições de campo. Fitopatologia Brasileira 29:39-46. 2004a.

CHAVES, M.S., MARTINELLI, J.A. \& FEDERIZZI, L.C. Resistência quantitativa à ferrugem da folha em genótipos de aveia branca: II - Avaliação de componentes de resistência. Fitopatologia Brasileira 29:47-55. 2004b.

HABTU, A. \& ZADOKS, J.C. Components of partial resistance in Phaseolus beans against an Ethiopian isolate of bean rust. Euphytica 83:95-102. 1995.

IAMSUPASIT, N., CHAKRABORTY, S. \& CAMERON, D.F. Components of quantitative resistance to anthracnose (Colletotrichum gloeosporioides) in tetraploid accessions of the pasture legume Stylosanthes hamata. Australian Journal of Experimental Agriculture 33:855-860. 1993.

LORENZINI, G., SPARAGU, E. \& MARTINI, P. Analysis of components of resistance to Uromyces caryophyllinus in carnation. Advances in Horticultural Science 13:51-55. 1999.

NEERVOORT, W.J. \& PARLEVLIET, J.E. Partial resistance of barley to leaf rust Puccinia hordei. V. Analysis of the components of partial resistance in eight barley cultivars. Euphytica 27:33-39. 1978.

OHM, J.W. \& SHANER, G.E. Three components of slow leaf-rusting at different growth stages in wheat. Phytopathology 66:1356-1360. 1976.

PARLEVLIET, J.E. Components of resistance that reduce the rate of epidemic development. Annual Review of Phytopathology 17:203222. 1979.

PARLEVLIET, J.E. Resistance of the nonrace-specific type. In: Bushnell, W.R. \& Roelfs, A.P. (Eds.) The Cereal Rusts:Diseases, distribution, epidemiology and control. New York. Academic Press. 1985. pp.501-525.

PARLEVLIET, J.E. Strategies for the utilization of partial resistance for the control of cereal rusts. In: Simmonds, N.W. \& Rajaram, S. (Eds.) Breeding Strategies for Resistance to the Rusts of Wheat. Mexico, D.F. CIMMYT. 1988. pp.48-62.

RIBEIRO JUNIOR, J.I., BARBOSA, H.M. \& ZAMBOLIM, L. Resistência a Uromyces phaseoli var. typica Arth. em mutantes de feijão (Phaseolus vulgaris L.). Revistas Ceres 40:305-313. 1993. 
SZTEJNBERG, A. \& WAHL, I. Mechanisms and stability of slow stem rusting resistance in Avena sterilis. Phytopathology 66:74-80. 1976.

THOMÉ, G.C.H., MILACH, S.C.K. \& VOLK, L.B. da S. Tamanho de pústula:um componente importante da resistência parcial à ferrugem da folha em aveia. Summa Phytopathologica 23:262-264.
1997.

WAHL, I., WILCOXSON, R.D. \& ROWELL, J.B. Slow rusting of wheat with stem rust detected in the glasshouse. Plant Disease 64:5456. 1980.

ZONTA, E.P. \& MACHADO, A. SANEST. Sistema de Análise Estatística para Microcomputadores. Disquete 3,5” Pelotas. 1984. 